10

\title{
Особенности взаимодействия в водных растворах молекул поливинилпирролидона с ионами цинка и серебра по данным ИК спектроскопии
}

\author{
(C) Н.А. Волкова ${ }^{1}$, С.К. Евстропьев ${ }^{1,2, \uparrow}$, Н.В. Никоноров ${ }^{1}$, К.С. Евстропьев ${ }^{1}$ \\ ${ }^{1}$ Университет ИТМО, \\ 197101 Санкт-Петербург, Россия \\ ${ }^{2}$ Санкт-Петербургский государственный технологический институт (Технический университет), \\ 190013 Санкт-Петербург, Россия \\ ฯ e-mail: evstropiev@bk.ru \\ Поступила в редакцию 04.04.2019 г. \\ В окончательной редакции 04.04.2019 г. \\ Принята к публикации 11.04.2019 г.
}

\begin{abstract}
Приведены результаты исследования методом ИК спектроскопии водных растворов, содержащих поливинилпирролидон и нитраты цинка и серебра. Исследования показали, что введение нитратов цинка и серебра в растворы поливинилпирролидона приводит к сдвигу полос поглощения полимера в область меньших волновых чисел. Полученные результаты свидетельствуют о возможности образования комплексов, состоящих из молекул полимера и ионов металлов.
\end{abstract}

Ключевые слова: ИК спектроскопия, спектр поглощения, поливинилпирролидон, ионы металлов.

DOI: $10.21883 /$ OS.2019.10.48377.128-19

\section{Введение}

Поливинилпирролидон (ПВП) является одним из наиболее распространенных растворимых полимеров, применяемых при синтезе и использовании различных наноматериалов в фотонике и медицине [1-6]. Важной особенностью этого полимера является наличие в его структуре пирролидонового цикла (рис. 1), включающего атом азота с неподеленной электронной парой, а также карбонильную группу $\mathrm{C}=\mathrm{O}$. Эта структурная особенность ПВП определяет его способность к образованию комплексов с ионами переходных металлов $\left(\mathrm{Co}^{2+}[7,8]\right.$, $\left.\mathrm{Ni}^{2+}[8,9]\right)$ и иода $[10]$, а также к стабилизации наночастиц различного химического состава [1-6,10-18].

Исследование роли различных структурных групп молекул полимера во взаимодействии ПВП с наночастицами являлось предметом многих исследований $[2,5,6,17,18]$.

Разбавленные растворы ПВП, содержащие соли цинка и серебра, часто используются для формирования различных наночастиц или применяются при получении покрытий [11,19-22]. Поэтому изучение структурных особенностей этих растворов является актуальной задачей.

Хорошо известно, что увеличение $\mathrm{pH}$ растворов ПВП и солей цинка приводит к образованию гидрооксида цинка и последующему формированию коллоидных растворов, содержащих наночастицы ZnO $[11,23,24]$. Этот процесс представляет собой простой и экономичный метод получения наноразмерных $\mathrm{ZnO}$ материалов, имеющих широкое практическое применение в фотонике, сенсорике, солнечной энергетике и медицине. Исследование изменений структуры компонентов растворов ПВП и солей цинка при увеличении их $\mathrm{pH}$ является важным этапом их оптимизации.

Целью настоящей работы являлось исследование методом ИК спектроскопии особенностей взаимодействия в водных растворах молекул ПВП с ионами цинка и серебра.

\section{Материалы и методы}

В качестве исходных материалов в работе использовались водные растворы $\mathrm{Zn}\left(\mathrm{NO}_{3}\right)_{2}(0.17 \mathrm{M}), \mathrm{AgNO}_{3}$ $\left(7.1 \cdot 10^{-3} \mathrm{M}\right)$ и ПВП $\left(3.9 \cdot 10^{-5} \mathrm{M}\right)$. Растворы смешивались в различных соотношениях при комнатной температуре с помощью магнитной мешалки. Химические составы полученных растворов приведены в таблице.

Измерения ИК спектров растворов осуществлялось с помощью фурье-спектрометра Bruker ALPHA.

\section{Экспериментальные результаты и обсуждения}

На рис. 2, а приведены ИК спектры водных растворов, содержащих ПВП (кривая 1) и ПВП с добавками нитрата цинка (кривые 2-4). При введении в растворы нитрата цинка наблюдается сильное увеличение поглощения в области $1300-1400 \mathrm{~cm}^{-1}$, что обусловлено увеличением содержания в них нитрат-анионов $\mathrm{NO}_{3}^{-}$, характеризующихся полосой поглощения при $1363 \mathrm{~cm}^{-1}$ [5]. 


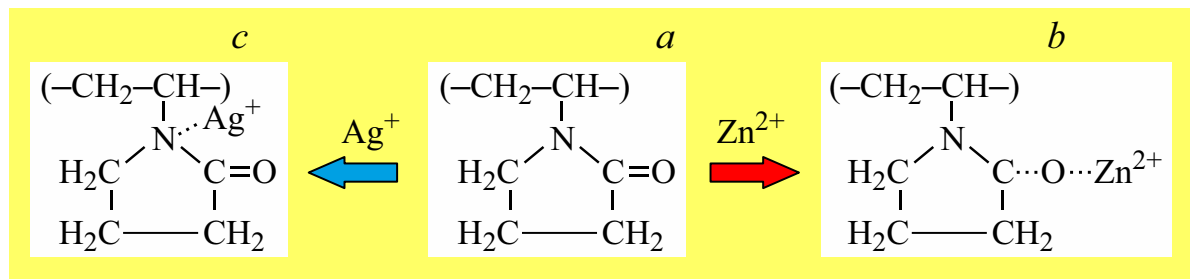

Рис. 1. Структурные формулы ПВП (a) и комплексов ПВП с ионами $\mathrm{Zn}^{2+}(b)$ и $\mathrm{Ag}^{+}(c)$.

Химические составы исследованных растворов

\begin{tabular}{c|c|c|c|c|c}
\hline \multirow{2}{*}{ Номер образца } & \multicolumn{5}{|c}{ Химический состав растворов, wt.\% } \\
\cline { 2 - 6 } & Вода & $\mathrm{Zn}\left(\mathrm{NO}_{3}\right)_{2}$ & $\mathrm{AgNO}_{3}$ & ПВП & $\mathrm{NH}_{4} \mathrm{OH}(10 \%$ раствор) \\
\hline 1 & 95.24 & - & - & 4.76 & - \\
2 & 96.62 & 1.00 & - & 2.38 & - \\
3 & 97.32 & 1.49 & - & 1.19 & - \\
4 & 96.20 & 0.70 & - & 3.10 & - \\
5 & 96.36 & - & 0.03 & 3.61 & - \\
6 & 96.82 & - & 0.04 & 3.14 & - \\
7 & 97.50 & - & 0.06 & 2.44 & - \\
10 & 98.68 & - & 0.09 & 1.23 & - \\
1 & 96.53 & 1.05 & 0.02 & 2.40 & - \\
13 & 97.08 & 0.46 & 0.04 & 2.42 & 2.40 \\
15 & 96.95 & 0.61 & 0.03 & 2.41 & 2.33 \\
\end{tabular}

Существенные изменения в ИК спектрах наблюдаются также в области колебаний карбонильной группы $\mathrm{C}=\mathrm{O}$ при $v=1637 \mathrm{~cm}^{-1}$. Добавки нитрата цинка к раствору ПВП приводят к постепенному уменьшению интенсивности этой полосы поглощения и ее сдвигу в область меньших волновых чисел. Увеличение соотношения между концентрациями $\mathrm{Zn}\left(\mathrm{NO}_{3}\right)_{2}$ и ПВП в растворах $\left(\left[\mathrm{Zn}\left(\mathrm{NO}_{3}\right)_{2}\right] /[\Pi \mathrm{В}]\right)$ усиливает наблюдаемые изменения в ИК спектрах (рис. 2, $a$ и таблица). Аналогичный характер изменений этой полосы поглощения наблюдался ранее при формировании комплексных соединений ПВП с ионами $\mathrm{Co}^{2+}$ [7] и $\mathrm{Ni}^{2+}$ [9], а также при образовании композитов ПВП с наночастицами $\mathrm{Fe}_{3} \mathrm{O}_{4}$ [6], $\mathrm{Ag}_{2} \mathrm{Se}[2]$, $\mathrm{ZnSe}[15]$ и $\mathrm{ZnS}$ [16]. Сдвиг полосы поглощения в область меньших значений волнового числа может быть обусловлен частичным ослаблением связи С-O в пирролидоновом цикле ПВП и свидетельствует об образовании связей между молекулами ПВП и ионами $\mathrm{Zn}^{2+}$ (рис. $1, b)$. Наблюдаемый небольшой спектральный сдвиг полосы колебаний $\mathrm{C}=\mathrm{O}$ обусловлен малым содержанием ионов $\mathrm{Zn}^{2+}$ в растворах относительно количества пирролидоновых циклов в молекулах ПВП (таблица).

Несколько иной характер изменений в ИК спектрах наблюдается при введении в растворы ПВП небольших количеств нитрата серебра (рис. 2,b). Интенсивность полосы поглощения группы $\mathrm{C}=\mathrm{O}$ уменьшается, но ее положение сохраняется неизменным. Заметное уменьшение интенсивности полос поглощения наблюдаются в области деформационных колебаний $\mathrm{CH}_{2}, \mathrm{C}-\mathrm{N}$ и $\mathrm{N}-\mathrm{H}\left(1420-1480 \mathrm{~cm}^{-1}\right)$ и валентных колебаний $\mathrm{C}-\mathrm{N}$ $\left(1280-1300 \mathrm{~cm}^{-1}\right)$. Увеличение содержания $\mathrm{AgNO}_{3}$ в растворах, так же как и $\mathrm{Zn}\left(\mathrm{NO}_{3}\right)_{2}$, усиливает изменения в ИК спектрах, хотя характер этих изменений несколько различается при добавках нитратов этих металлов (рис. 2, $a, b$ и таблица).

В [17] было установлено, что сильное взаимодействие атомов азота с маленькими (менее $50 \mathrm{~nm}$ ) наночастицами серебра, отражающееся в изменениях ИК спектра ПВП, обеспечивает стабилизацию этих наночастиц. Сдвиг полосы поглощения карбонильной группы $\mathrm{C}=\mathrm{O}$ наблюдался в [17] только при взаимодействии молекул ПВП с более крупными (500-1000 nm) частицами серебра. Наблюдаемые в настоящей работе изменения в спектрах ПВП при введении в раствор нитрата серебра подтверждают выводы, сделанные ранее в [17].

Сопоставление спектров растворов ПВП, содержащих $\mathrm{Zn}\left(\mathrm{NO}_{3}\right)_{2}$ (рис. 2,a) и $\mathrm{AgNO}_{3}$ (рис. 2,b), показывает существенное их различие в области поглощения анионов $\mathrm{NO}_{3}^{-}\left(1360-1390 \mathrm{~cm}^{-1}\right)$. Незначительность изменений в спектрах ПВП при введении в них нитрата серебра связана с относительно низкой концентрацией этого компонента (таблица). 

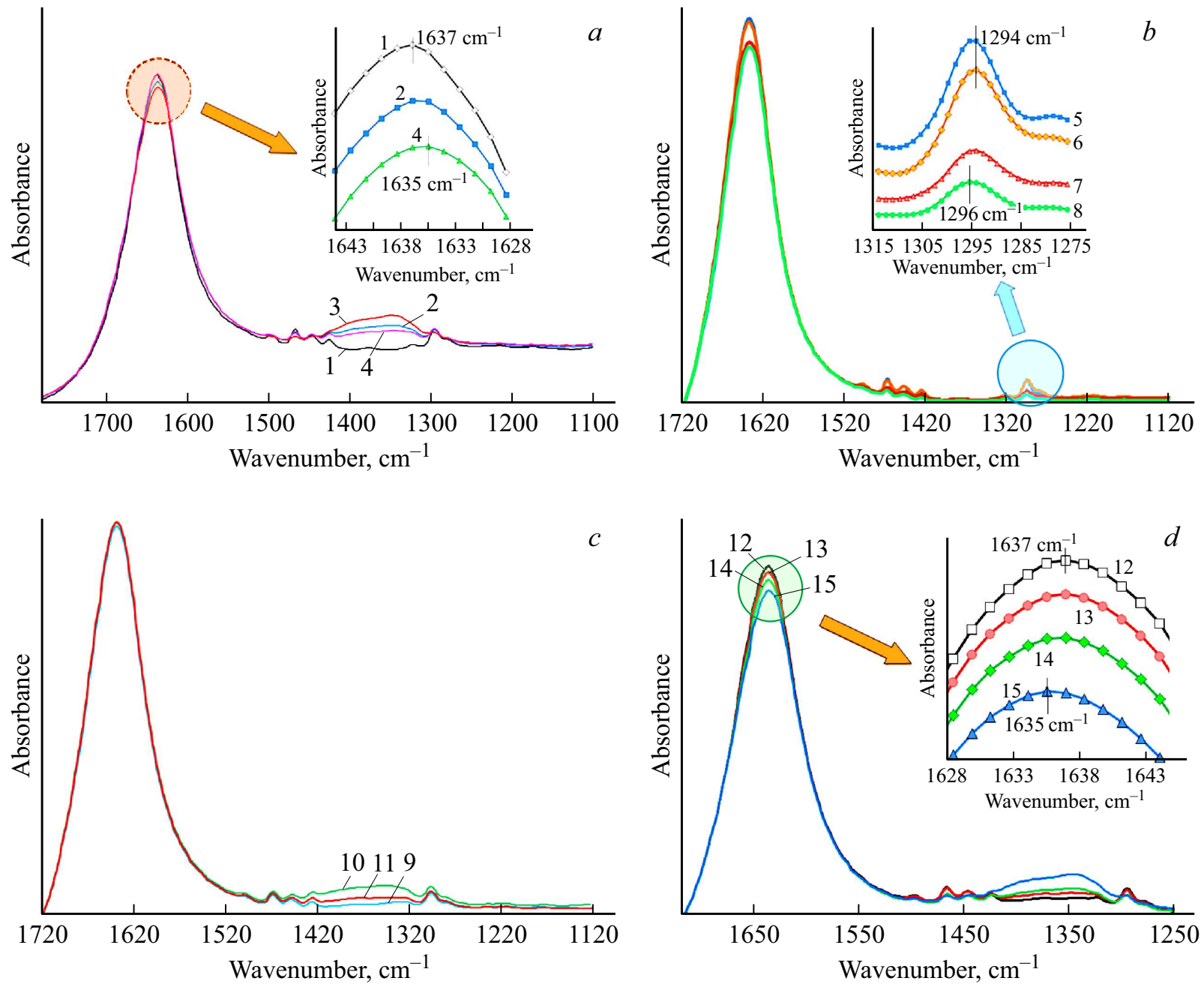

Рис. 2. ИК спектры поглощения растворов ПВП без добавок (1), растворов $2-4$ (см. таблицу) с добавками $\mathrm{Zn}\left(\mathrm{NO}_{3}\right)_{2}(a)$; растворов 5-8, содержащих $\mathrm{AgNO}_{3}(b)$; растворов 9-11, содержащих различные смеси нитратов цинка и серебра $(c)$ и растворов $12-15$, полученных при добавлении небольших количеств раствора $\mathrm{NH}_{4} \mathrm{OH}$ к растворам, содержащим ПВП и нитрат цинка $(d)$. Номера кривых на рисунках соответствуют номерам растворов в таблице.

На рис. 2,с представлены ИК спектры растворов ПВП, содержащие различные смеси нитратов цинка и серебра. Увеличение содержания нитрата цинка приводит к увеличению поглощения в области колебаний анионов $\mathrm{NO}_{3}^{-}\left(1360-1390 \mathrm{~cm}^{-1}\right)$, что обусловлено возрастанием концентрации этих ионов в растворах (таблица). Характер изменений в спектрах, наблюдаемых при введении в растворы ПВП смесей нитратов, полностью соответствует закономерностям, описанным выше.

На рис. 2, $d$ представлены ИК спектры растворов, полученных при добавлении небольших количеств раствора $\mathrm{NH}_{4} \mathrm{OH}$ к растворам, содержащим ПВП и нитрат цинка. Из сопоставления рис. $2, a$ и рис. $2, d$ видно, что эти добавки не изменяют особенности ИК спектров. В растворах с большим содержанием нитрата цинка интенсивность полосы поглощения анионов $\mathrm{NO}_{3}^{-}$заметно выше, а полоса поглощения карбонильной группы $\mathrm{C}=\mathrm{O}$ $\left(1637 \mathrm{~cm}^{-1}\right)$ несколько сдвинута в область меньших значений волнового числа и имеет заметно меньшую интенсивность.

\section{Выводы}

Исследования методом ИК спектроскопии показали, что введение нитратов цинка и серебра в водные растворы ПВП приводит к сдвигу полос поглощения полимера в область меньших волновых чисел. Полученные результаты свидетельствуют о возможности образования комплексов, состоящих из молекул полимера и ионов металлов.

\section{Финансирование работы}

Работа была частично (С.К. Евстропьев) поддержана грантом Российского научного фонда № 19-19-00596. 


\section{Конфликт интересов}

Авторы заявляют, что у них нет конфликта интересов

\section{Список литературы}

[1] Koczkur K.M., Mourdikoudis S., Polavarapu L., Skrabalak S.E. // Dalton Transactions. 2015. V. 44. N 41. P. $17883-$ 17905.

[2] Liu H., Zhang B., Shi H., Tang Y., Jiao K., Fu X. // J. Mater. Chem. 2008. V. 18. P. 2573-2580.

[3] Kulagina A.S., Evstrop'ev S.K., Rosanov N.N., Vlasov V.V. // Semiconductors. 2018. V. 52. N 8. P. 997-1003.

[4] Evstropiev S.K., Kislyakov I.M., Bagrov I.V., Belousova I.M. // Polym. Adv. Technol. 2016. V. 27. P. 314-317. doi 10.1002/pat.3642

[5] Kan Caixia, Cai Weiping, Li Cuncheng, Zhang Lide // J. Mater. Res. 2005. V. 20. N 5. P. 320-324.

[6] Zhang Ying, Liu Jing-Ying, Ma Song, Zhang Ya-Jing, Zhao Xiang, Zhang Xiang-Dong, Zhang Zhi-Dong // J. Mater. Sci.: Mater. Med. 2010. V. 21. P. 1205-1210.

[7] Anasuya K.V., Veeraiah M.K., Prasannakumar S., Hemalatha P., Manju M. // Indian J. Adv. Chem. Sci. 2014. V. 2. P. $12-15$.

[8] Naseri M., Dehzangi A., Kamari H.M., See A., Abedi M., Salasi R., Goli-Kand A.N., Dianat P., Larki F., Abedini A., Hassan J., Far A.K., Majlis B.Y. // Metals. 2016. V. 6. N 8. P. 181.

[9] Anasuya K.V., Veeraiah M.K., Hemalatha P., Manju M. // IOSR J. Appl. Chem. (IOSR-JAC) e-ISSN: 2278-5736. V. 7. N 8. Ver. I (Aug. 2014). P. 61-66. www.iosrjournals.org.

[10] Borodko Y., Habas S.E., Koebel M., Yang P., Frei H., Somorjai G.A. // J. Phys. Chem. B. 2006. V. 110. N 48. P. 23052-23059.

[11] Guo Lin, Yang Shihe, Yang Chulei, Yu Ping, Wang Jiannong, Ge Weikun, Wong George K.L. // Appl. Phys. Lett. 2000. V. 76. N 20. P. 2901-2903.

[12] Wang Hongshui, Qiao Xueliang, Chen Jianguo, Wang Xiaojian, Ding Shiyuan // Mater. Chem. Phys. 2005. V. 94. P. 449-453.

[13] Евстропьев К.С., Гатчин Ю.А., Евстропьев С.К., Дукельский К.В., Кисляков И.М., Пегасова Н.А., Багров И.В. // Опт. и спектр. 2016. Т. 120. № 3. С. 434-441. Evstrop'ev K.S., Gatchin Yu.A., Evstrop'ev S.K., Dukel'skii K.V., Kislyakov I.M., Pegasova N.A., Bagrov I.V. // Opt. Spectrosc. 2016. V. 120. N 3. P. 415-422. doi $10.7868 / \mathrm{S} 003040341603006$

[14] Евстропьев С.К., Гатчин Ю.А., Евстропьев К.С., Дукельский К.В., Кисляков И.М. // Опт. и спектр. 2015. T. 119. № 6. C. 71-76. Evstrop'ev S.K., Gatchin Yu.A., Evstrop'ev K.S., Dukel'skii K.V., Kislyakov I.M. // Opt. Spectrosc. 2015. V. 119. N 6. P. 943-947.

[15] Divyasree M.C., Shiju E., Francis Jaismon, Anusha P.T., Venugopal Rao S., Chandrasekharan K. // Mater. Chem. Phys. 2017. V. 197. P. 208-214.

[16] Soltani N., Saion E., Erfani M., Rezaee K., Bahmanrokh G., Drummen G.P.C., Bahrami A., Hussein M.Z. // Int. J. Mol. Sci. 2012. V. 13. P. 12412-12427. doi 10.3390/ijms 131012412

[17] Wang Hongshui, Qiao Xueliang, Chen Jianguo, Wang Xiaojian, Ding Shiyuan // Mater. Chem. Phys. 2005. V. 94. P. 449-453.
[18] Zhang Zongtao, Zhao Bin, Hu Liming // J. Solid State Chem. 1996. V. 121. N 1. P. 105-110. doi 10.1006/jssc.1996.0015

[19] Истомина О.В., Евстропьев С.К., Колобкова Е.В., Тробимов А.О. // Опт. и спектр. 2018. Т. 124. № 6. C. 742-746. Istomina O.V., Evstropiev S.K., Kolobkova E.V., Trofimov A.O. // Opt. Spectrosc. 2018. V. 124. N 6. P. 774-778.

[20] Dhanalakshmi A., Amutha C., Lawrence B., Kulathuraan K., Ramadas V., Natarajan B. // Int. J. Current Research. 2013. V. 5. N 11. P. 3408-3413.

[21] Tachikawa Shingo, Noguchi Atsushi, Tsuge Takeharu, Hara Masahiko, Odawara Osamu, Wada Hiroyki /I Materials. 2011. V. 4. P. 1132-1143. doi 10.3390/ma4061132

[22] Evstropiev S.K., Gatchin Yu.A., Evstropyev K.S., Romanova E.B. // Opt. Engineering 2016. V. 55. N 4. 047108.

[23] Gutul T., Rusu E., Condur N., Ursaki V., Goncearenco E., Vlazan P. // Beilstein J. Nanotechnol. 2014. V. 5. P. 402-406. doi 10.3762/bjnano.5.47

[24] Evstropiev S.K., Vasilyev V.N., Nikonorov N.V., Kolobkova E.V., Volkova N.A., Boltenkov I.A. // Chem. Engineering and Processing: Process Intensification. 2018. V. 134. P. 45-50. doi 10.1016/j.cep.2018.10.020. 